\title{
Pneumonia following antipsychotic prescriptions in electronic health records: a patient safety concern?
}

Kristina Star, Andrew Bate, Ronald HB Meyboom and I Ralph Edwards

\begin{abstract}
Background

In screening the Intercontinental Medical Statistics (IMS) Health Disease Analyzer database of GP records from the UK, an increased registration of pneumonia subsequent to the prescription of some antipsychotic medicines was identified.

Aim

To investigate the temporal pattern between antipsychotic prescriptions and pneumonia with respect to age, type of pneumonia and other chest infections, and antipsychotic class.

Design of study

Self-controlled cohort analysis.

Setting

Electronic health records from the UK IMS Health Disease Analyzer database.

\section{Method}

Three groups of pneumonia-related International Classification of Diseases (ICD)-10 terms and prescriptions of atypical and conventional antipsychotic medicines were studied. Separate analyses were carried out for patients aged $\geq 65$ years. The observed rate of pneumonia terms registered in different time periods in connection to antipsychotic prescriptions was contrasted to the overall rate of pneumonia terms relative to prescriptions of other drugs in the same dataset.

\section{Results}

In patients aged $\geq 65$ years, an increased registration of a group of terms defined as 'acute chest infections', after atypical antipsychotic prescriptions, was identified. The corresponding increase after conventional antipsychotic prescriptions was much smaller. Bronchopneumonia had a striking increase after both atypical and conventional antipsychotic prescriptions, and was commonly recorded with fatal outcome. Few registrations of hypostatic pneumonia were noted. Patients aged $<65$ years did not have a higher rate of acute chest infections after receiving antipsychotic prescriptions.

\section{Conclusion}

The consistent pattern of an increased rate of chest infections after atypical antipsychotic prescriptions in older people seen in this outpatient study, together with the higher risk shown in a previous study on hospitalised patients, suggests a causal relationship. This is of importance since bronchopneumonia seems highly linked to fatal outcome. In the absence of a mechanism, further investigation of the role of antipsychotics in older people is needed.

\section{Keywords}

aged; antipsychotic agents; computerised medical records systems; pneumonia.
\end{abstract}

\section{INTRODUCTION}

Pneumonia can result in serious consequences, particularly in patients who are old and frail. The higher risk of death in older patients with dementia using antipsychotic medicines, ${ }^{1-2}$ shown in metaanalyses on placebo-controlled studies was, apart from heart-related events, due to infections such as pneumonia. ${ }^{1,3}$ These publications did not reveal details of pneumonia rates, comparing antipsychotic and placebo treatments.

Infections (mostly pneumonia) were the reason for non-cancer mortality in $10 \%$ of new users of antipsychotics in a large database cohort study on older people and, compared with users of atypical antipsychotics, the group using conventional antipsychotics showed a higher incidence (although not statistically significant) of pneumonia-related

K Star, BSc, drug safety analyst, Uppsala Monitoring Centre, WHO Collaborating Centre for International Drug Monitoring (WHO CCIDM); Public Health and Caring Sciences, Uppsala University, Uppsala, Sweden. A Bate, PhD, manager (until 3 Aug 2009), Uppsala Monitoring Centre, WHO CCIDM, Sweden; Computing and Mathematics, Brunel University, London. RHB Meyboom, MD, PhD, medical advisor, Uppsala Monitoring Centre, WHO CCIDM, Sweden; Division of Pharmacoepidemiology and Pharmacotherapy, Utrecht University, Utrecht, The Netherlands. IR Edwards, MRCS, FRCP, FRACP, medical advisor, Uppsala Monitoring Centre, WHO CCIDM, Sweden.

Address for correspondence

Kristina Star, WHO Collaborating Centre for International Drug Monitoring, Uppsala Monitoring Centre, Research

Department, Box 1051, Uppsala, 75140, Sweden.

E-mail: kristina.star@who-umc.org

Submitted: 23 April 2009; Editor's response: 15 July 2009; final acceptance: 10 March 2010.

(c)British Journal of General Practice

This is the full-length article of an abridged version published in print. Cite this article as: Br J Gen Pract 2010; DOI: 10.3399/bjgp10X532396. 
mortality. ${ }^{4}$ A US study of users of antipsychotics who were admitted to the hospital for pneumonia showed a higher mortality rate for those who used conventional, rather than atypical, antipsychotics. ${ }^{5}$ Antipsychotic use - in the case of the conventional group - among patients with Alzheimer's disease has shown to be a risk factor for aspiration pneumonia due to a noted drug effect on the swallowing reflex. ${ }^{6}$

Older patients currently using antipsychotic medicines, when compared with those not currently using them, were noted to be at higher risk for pneumonia with an adjusted odds ratio of 1.6 (95\% confidence interval $[\mathrm{Cl}]=1.3$ to 2.1 ) in a nested case control study on pharmacy dispensing and hospital discharge registrations. ${ }^{7}$ Users of atypical antipsychotics showed a higher risk for pneumonia than users of conventional antipsychotics.

In prescribing information of antipsychotic drugs, ${ }^{8}$ pneumonia is most often described in connection with the increased risk of death in older people with dementia, or listed as aspiration pneumonia. Further details of pneumonia in association to antipsychotic use are limited.

When screening the Intercontinental Medical Statistics (IMS) Health Disease Analyzer database of GP records from the UK, a finding that pneumonia was registered more frequently than expected after the introduction of risperidone prompted further investigation of the temporal pattern between any antipsychotic drug prescription and pneumoniarelated terms, particularly in patients aged $\geq 65$ years.

\section{METHOD}

The UK IMS Health Disease Analyzer dataset used contained information of prescriptions and medical records of more than 2 million patients from different GP practices in the UK. Medical problems and notes are coded on entry by the GP using Read Codes. These Read Codes are mapped by IMS Health to the International Classification of Diseases (ICD)-10 terminology and defined in this analysis as 'medical events'. Data quality is maintained by the presence of data-quality markers in the database; collated information from the markers is used to feed back to GPs, which helps maintain and improve data quality in the database. ${ }^{9}$

The pattern-discovery method for longitudinal patient records, previously described in Norén et al, ${ }^{10}$ was applied on the UK IMS Health Disease Analyzer dataset as of 1 January 2006. The method contrasts the observed rate of registration of a medical event (here a pneumonia-related ICD-10 term) in various time periods relative to the prescription of a drug (here antipsychotics), to the overall registration rate of the same medical event, relative to prescriptions

\section{How this fits in}

A previous study showed an increased risk of pneumonia in older patients currently using antipsychotic drugs in the Netherlands, based on prescription data and hospital discharge records. The current analysis offers a unique possibility to view patterns in records of pneumonia and other chest infections, both before and after antipsychotics were prescribed, in outpatient general practice. In patients aged $\geq 65$ years, an increased registration of chest infections subsequent to the prescription of atypical antipsychotics was noted, relative to the rate in the same patients preceding the prescription.

of other drugs in the same data. For each time period of interest (the results presented are for monthly intervals), a measure of association - referred to as the Information Component (IC) - is computed. This indicates whether the medical event is registered unexpectedly frequently $(\mathrm{IC}>0)$, unexpectedly rarely $(\mathrm{IC}<0)$ or as often as can be expected $(\mathrm{IC}=0)$ in a given time period, based on the overall registration rate for the event relative to other drugs.

A graphical representation of the IC values, along with observed and expected numbers of events in different time periods, provides an overview of the temporal relationship between two events; this is referred to as a chronograph. To screen for patterns of temporal association, an IC $\mathrm{C}_{\Delta}$ value is computed that contrasts the IC value in the month immediately after a prescription with the IC value in a 6-month control period centred 2 years prior. For both IC and $\mathrm{IC}_{\Delta}$, a combination of statistical shrinkage and uncertainty intervals is used to reduce the risk of highlighting spurious associations. The lower limit of the 95\% credibility interval is referred to as $\mathrm{IC}_{025}$ for the $\mathrm{IC}$ and as $\mathrm{IC}_{\Delta 025}$ for $\mathrm{IC}_{\Delta}$.

To avoid dominance of repeat prescriptions, the analysis was restricted to new prescriptions of the antipsychotic medicine, defined as the first record of the drug prescription over a course of 13 months. Drugs within the European Pharmaceutical Market Research Association's anatomical classification of pharmaceutical products ${ }^{11}$ - the atypical (N05A1) and conventional antipsychotic (N05A9) groups were used. The pneumonia-related ICD-10 terms were grouped and will be referred to in this article as follows:

- 'acute chest infections' (ICD codes J110, J12x16x, J181, 188, 189, J220);

- bronchopneumonia (J180); and

- 'hypostatic pneumonia' (J182, J69x).

The acute chest infections group was defined as being rather inclusive, for example, as for 'unspecified acute lower respiratory infection' (J220). Graphs labelled 'pneumonia and other chest infections' include all ICD-10 terms used in this study. 


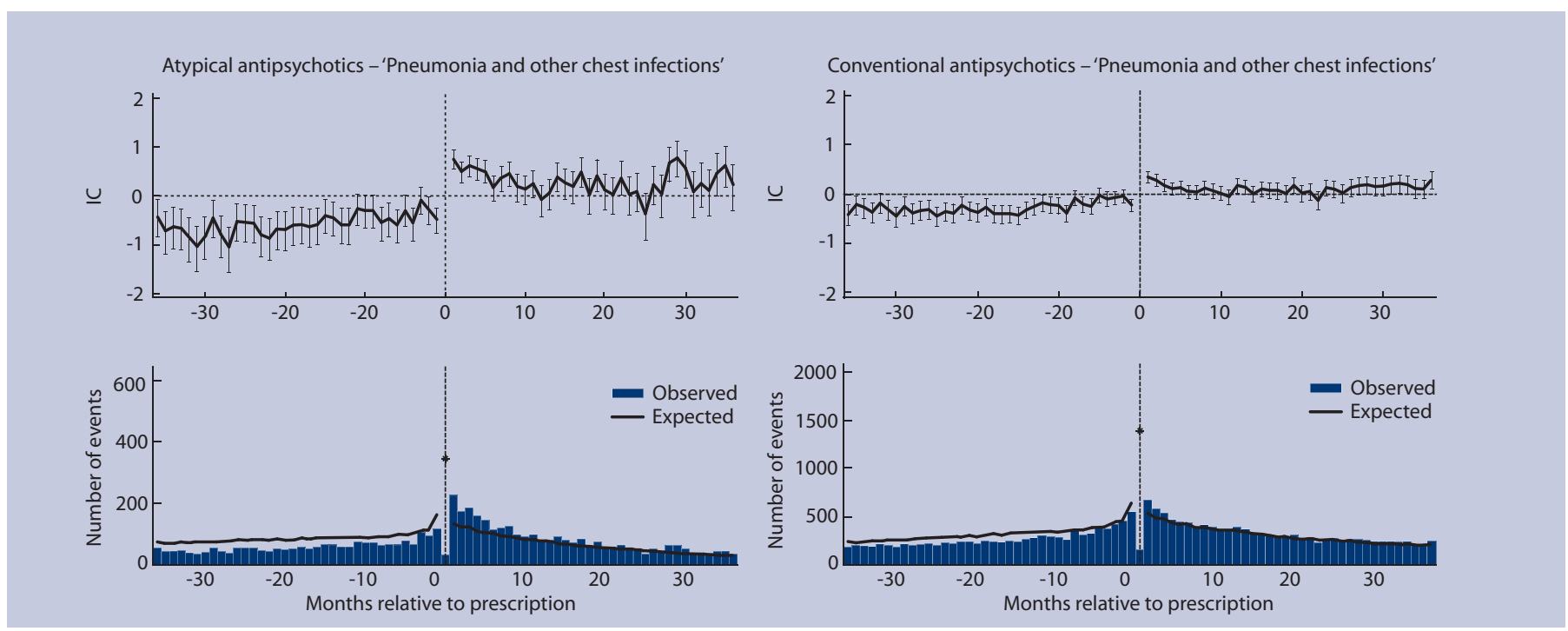

Figure 1. Chronographs for records of 'pneumonia and other chest infections' relative to atypical and conventional antipsychotic prescriptions for all ages. IC value on the day (month $=0$ ) for the IC graph was below -2 and outside the scale.

Figure 2. Chronographs for records of acute chest infections relative to atypical and conventional antipsychotic prescriptions for ages $\geq 65$ years. IC value on the day (month $=$ 0) for the IC graph was below -2 and outside the scale.
Appendices 1, 2 and 3 give a complete listing of all the ICD-10 codes with the names specified, as well as the linked Read Codes within each group of ICD-10 codes that were used in the search. The age groups used were 18-64 years and $\geq 65$ years.

Details of the patients linked with pneumoniarelated terms that were recorded within the month after an atypical or conventional antipsychotic prescription were also reviewed.

\section{RESULTS}

\section{Pneumonia and other chest infections over} time: chronographs

The figures with chronographs display monthly registrations of the different pneumonia-related term groupings, 3 years before and after atypical and conventional antipsychotic prescriptions. The lower panel of the figure displays a graphical overview of the observed and expected numbers of pneumonia registrations in different time periods relative to the antipsychotic prescription; the upper panel shows the corresponding relative rate with IC values.

Figure 1 shows the temporal pattern for 'pneumonia and other chest infections' recorded relative to atypical and conventional antipsychotic prescriptions for all ages. A sudden increase in the recording rate of pneumonia-related terms was noted after an antipsychotic prescription, compared with the period prior to prescription. Compared with patients with other prescriptions, a higher relative recording rate of the pneumonia-related terms was noted after antipsychotic prescriptions.

Figure 2 displays the chronographs for acute chest infections recorded before and after atypical and conventional antipsychotic prescriptions for patients aged $\geq 65$ years. The corresponding result for patients aged 18-64 years is shown in Figure 3. For patients aged $\geq 65$ years, there was an unexpectedly higher relative rate of terms within the acute chest infections group, recorded after atypical

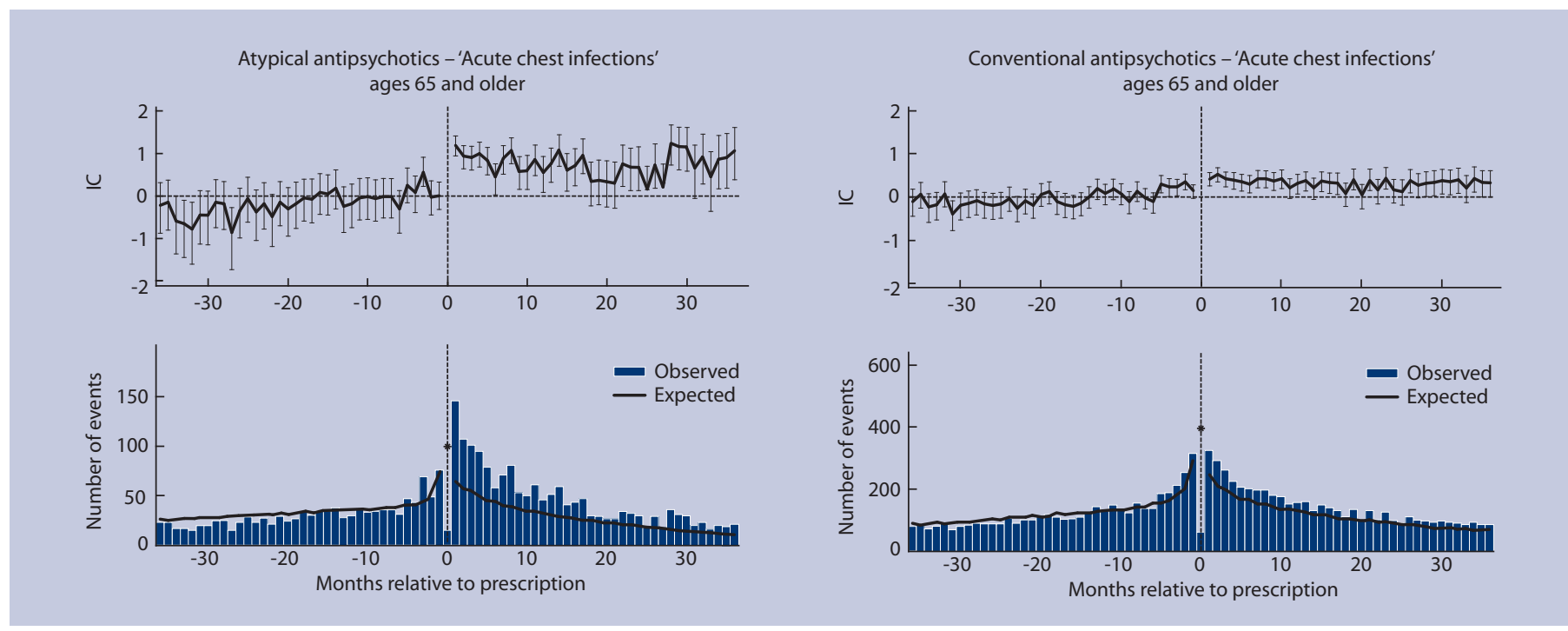



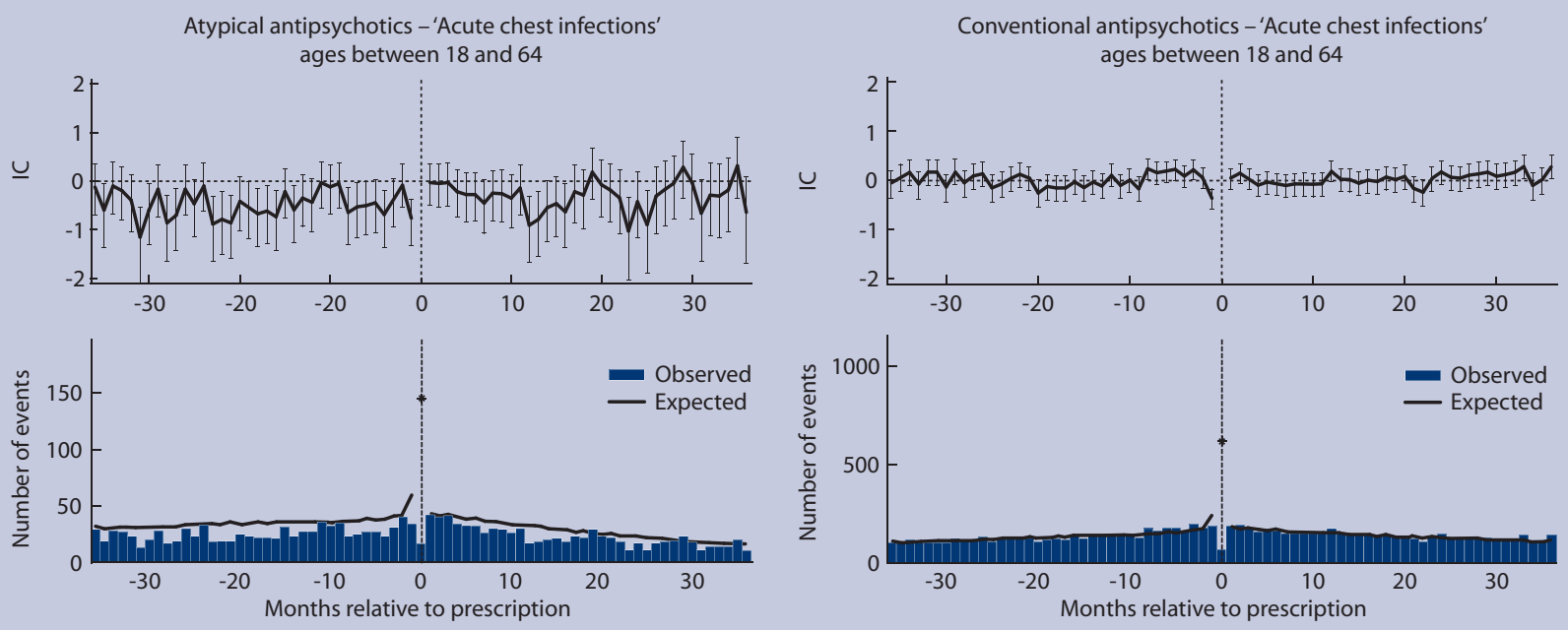

antipsychotic prescriptions, compared with before. For the conventional antipsychotics, the difference of acute chest infections before and after prescription was much smaller.

The temporal pattern for bronchopneumonia in patients aged $\geq 65$ years was similar for atypical and conventional antipsychotic prescriptions, with a relative increase of registrations in the month after prescription, continuing for several months (Figure 4). In the years preceding the antipsychotic prescription, there were few registrations of bronchopneumonia, resulting in a fluctuating relative rate, although for the conventional antipsychotics the relative rate had already been increasing before prescription took place.

The hypostatic pneumonia group, including aspiration pneumonitis, had few registrations of this category, particularly in the atypical antipsychotic group (Figure 5). The conventional antipsychotics had an elevated relative rate on day of prescription that continued at a similar level during the months after prescription.

The temporal patterns between the antipsychotics and the pneumonia-related terms, as seen in the above analyses, remained also when limiting the data to patients aged $\geq 80$ years.

An increase of amoxicillin prescriptions was seen after atypical antipsychotic prescriptions, confirming the temporal pattern seen for acute chest infections subsequent to the same antipsychotic class (Figure 6). This was not seen for the conventional antipsychotics.

\section{Review of patients aged $\geq 65$ years with} pneumonia-related terms recorded within the month after an antipsychotic prescription

The account of details in this section regards the prescriptions for patients aged $\geq 65$ years who had a pneumonia-related term recorded within the month after the antipsychotic prescription. The type and number of atypical and conventional antipsychotic
Figure 3. Chronographs for records of acute chest infections relative to atypical and conventional antipsychotic prescriptions for ages 18-64 years. IC value on the day (month=0) for the IC graph was below -2 and outside the scale.

Figure 4. Chronographs

for records of bronchpneumonia relative to atypical and conventional antipsychotic prescriptions for ages $\geq 65$ years.
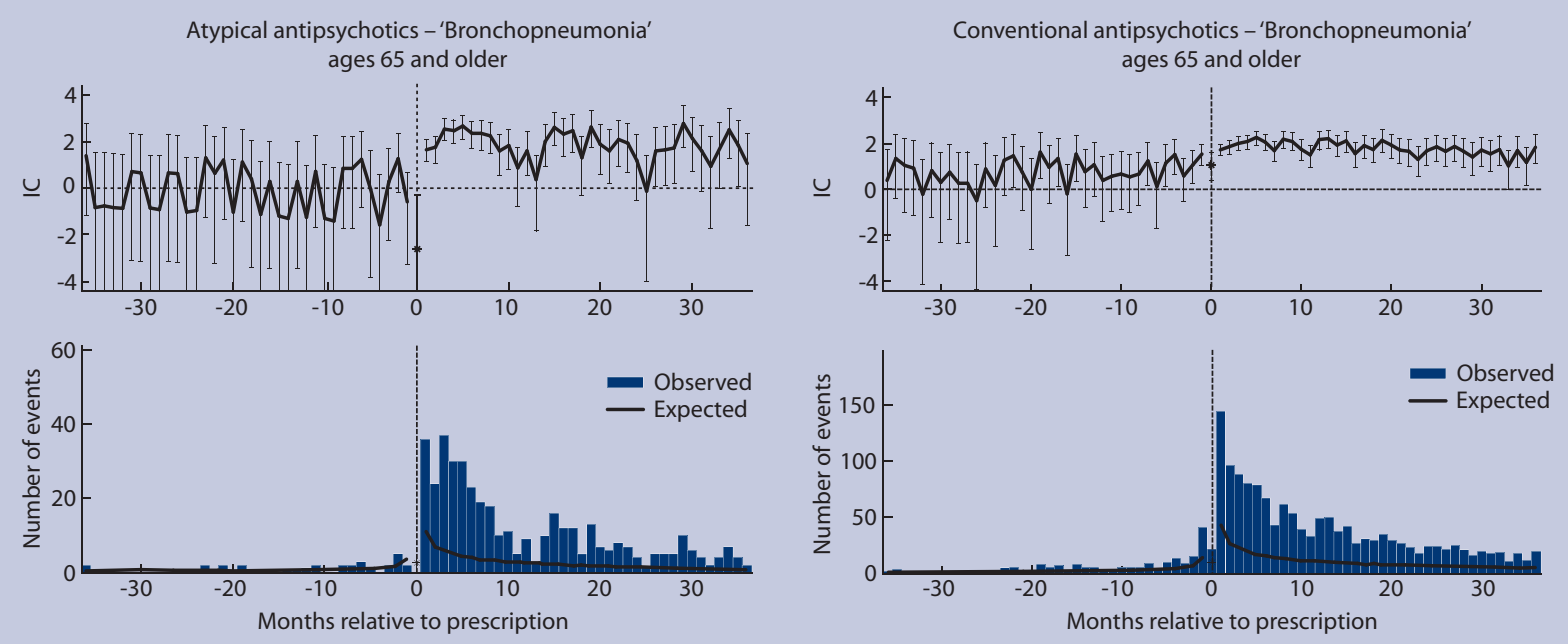
Atypical antipsychotics - 'Hypostatic pneumonia' ages 65 and older
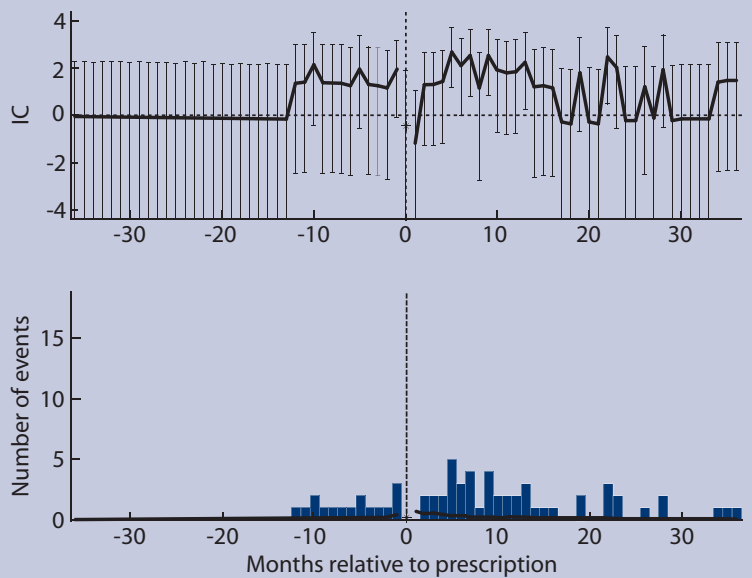

Conventional antipsychotics - 'Hypostatic pneumonia' ages 65 and older
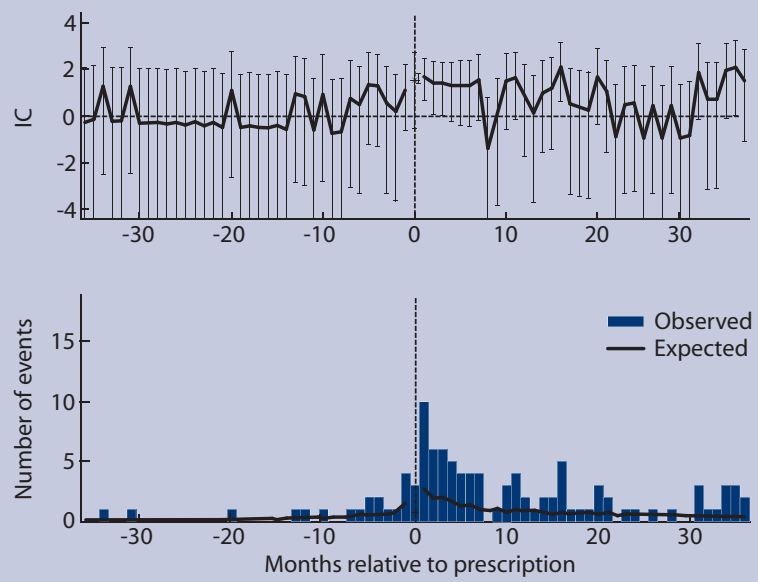

Figure 5. Chronographs for records of hypostatic pneumonia relative to atypical and conventional antipsychotic prescriptions for ages $\geq 65$ years.

Figure 6. Chronographs for the prescription amoxicillin relative to atypical and conventional antipsychotic prescriptions for ages $\geq 65$ years. prescriptions represented in each antipsychotic class for this group of patients is given in Table 1. The atypical and conventional antipsychotic prescriptions were, to a large extent, represented by risperidone and thioridazine respectively, which were also the top prescribed antipsychotics in the dataset.

The ICD-10 term that was mostly represented within the acute chest infections group in the month after prescription was 'unspecified acute lower respiratory infection' for both atypical and conventional antipsychotics (Table 2).

The median age for patients aged $\geq 65$ years with registrations of acute chest infections terms in the month after atypical and conventional antipsychotic prescription was 85 and 83 years, respectively. The corresponding median age for bronchopneumonia was 83.5 years for atypical prescriptions and 84 years for conventional antipsychotic prescriptions.

To increase understanding of the outcomes in the patients ( $\geq 65$ years) who had acute chest infections and bronchopneumonia in the month after prescription, the rate of deregistrations in these patient histories were reviewed from time of antipsychotic prescription until the end of the month. A total of $86 \%$ of the patients with bronchopneumonia were deregistered within the month after an atypical antipsychotic prescription. The corresponding percentage for the patients with conventional antipsychotic prescriptions was $71 \%$. The deregistration rate for patients with acute chest infections was $15 \%$ within the month after an atypical prescription and $20 \%$ after a conventional antipsychotic prescription. Death was the most common reason for deregistration.

\section{DISCUSSION}

\section{Summary of main findings}

In patients aged $\geq 65$ years, an increased registration of acute chest infections subsequent to atypical
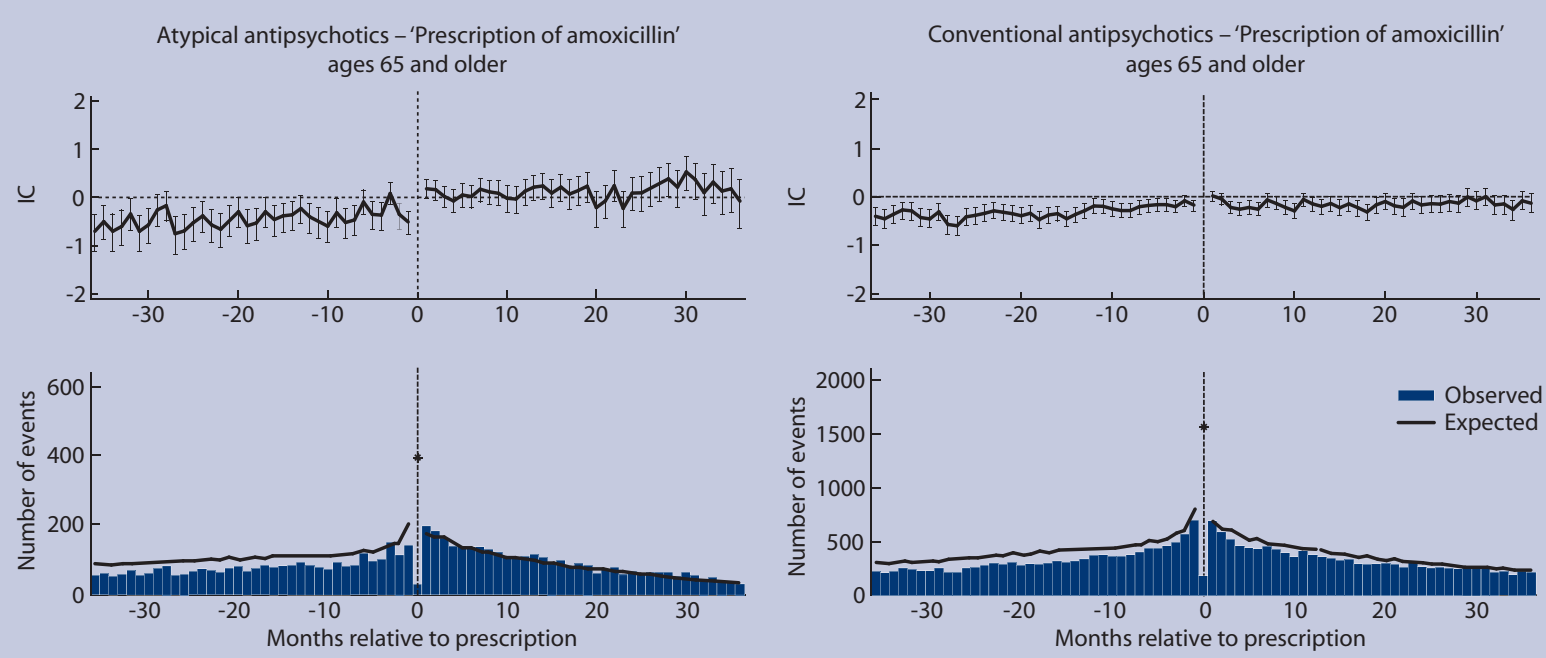
antipsychotic prescriptions was noted relative to the rate in the same patients prior to the prescription. An increased rate of acute chest infections was seen also relative to the background of older people having been prescribed other medications. The corresponding increase after conventional antipsychotic prescriptions was much smaller. Patients aged $<65$ years did not have a higher rate of chest infections after antipsychotic prescriptions, be they atypical or conventional.

Bronchopneumonia had a striking and persistent increase in the follow-up period after both atypical and conventional antipsychotic prescriptions. There was, however, an increase in the relative rate of bronchopneumonia before conventional antipsychotic prescriptions. Registrations of bronchopneumonia subsequent to antipsychotic prescriptions were also highly associated with records indicating death.

An elevated rate of registrations was noted for hypostatic pneumonia around the time of conventional antipsychotic prescriptions. This group of terms had few registrations, particularly for atypical prescriptions, making the evaluation more uncertain.

\section{Strengths and limitations of this study}

The recorded diagnosis of pneumonia and related terms in this study of electronic health records is based on clinical evidence and not confirmed by radiological, or any other, tests. The study is dependent on the codes assigned by GPs and could be subject to misclassification bias. As for any study based on issued prescription records, it is not known if the patient actually took the medication prescribed. Observational data will commonly be unsatisfactory, to various degrees, because it is not collected for a specific research reason; on the other hand, it reflects the way normal clinical practice is done, rather than ideal interventions, which may not be generalisable.

Due to the dataset used in this study, the results do not represent all types of antipsychotic drugs. Some antipsychotics dominated more than others and some drugs, such as clozapine, had very few prescriptions. Thioridazine was noted to be a commonly prescribed conventional antipsychotic in this data; however, this drug has been withdrawn in many countries, including the UK, due to its adverse cardiac effects. ${ }^{12}$ However, when this drug was excluded from the analysis it made no difference to the overall results. It is also important to consider the heterogeneity of the various drugs represented within the atypical and conventional antipsychotic classes in this study, as well as the limitations of using the current groupings of antipsychotic drugs as highlighted by Leucht et al. ${ }^{13}$

\begin{tabular}{|c|c|c|c|}
\hline & $\begin{array}{l}\text { Acute chest } \\
\text { infections }\end{array}$ & Bronchopneumonia & $\begin{array}{l}\text { Hypostatic } \\
\text { pneumonia }\end{array}$ \\
\hline \multicolumn{4}{|c|}{ Atypical antipsychotics } \\
\hline Risperidone & 103 & 27 & 0 \\
\hline Olanzapine & 25 & 9 & 0 \\
\hline Quetiapine & 16 & 0 & 0 \\
\hline Amisulpride & 2 & 0 & 0 \\
\hline Total atypical & 146 & 36 & 0 \\
\hline \multicolumn{4}{|c|}{ Conventional antipsychotics } \\
\hline Thioridazine & 117 & 62 & 3 \\
\hline Haloperidol & 77 & 37 & 3 \\
\hline Promazine & 37 & 8 & 2 \\
\hline Chlorpromazine & 30 & 17 & 1 \\
\hline Trifluoperazine & 22 & 2 & 1 \\
\hline Flupentixol & 17 & 3 & 0 \\
\hline Sulpiride & 10 & 2 & 0 \\
\hline Levomepromazine & 5 & 8 & 0 \\
\hline Zuclopenthixol & 4 & 1 & 0 \\
\hline Droperidol & 3 & 1 & 0 \\
\hline Perphenazine & 2 & 1 & 0 \\
\hline Benperidol & 2 & 0 & 0 \\
\hline Fluphenazine & 0 & 1 & 0 \\
\hline Fluspirilene & 0 & 1 & 0 \\
\hline Total conventional & 326 & 144 & 10 \\
\hline
\end{tabular}

Table 2. ICD-10 terms for patients in the 'acute chest infections' group recorded in the month after antipsychotic prescription, ages $\geq 65$ years.

\begin{tabular}{lcc}
$\begin{array}{l}\text { ICD-10 terms following } \\
\text { antipsychotic prescriptions }\end{array}$ & $\begin{array}{c}\text { Atypical } \\
\text { prescriptions }\end{array}$ & $\begin{array}{c}\text { Conventional } \\
\text { prescriptions }\end{array}$ \\
\hline Unspecified acute lower respiratory infection & 125 & 281 \\
\hline Pneumonia, unspecified & 15 & 31 \\
\hline Influenza with pneumonia, virus not identified & 3 & 2 \\
\hline Viral pneumonia, unspecified & 1 & 3 \\
\hline Pneumonia due to Streptococcus pneumoniae & 1 & 5 \\
\hline Other bacterial pneumonia & 1 & 1 \\
\hline Lobar pneumonia, unspecified & - & 2 \\
\hline Bacterial pneumonia, unspecified & - & 1 \\
\hline
\end{tabular}

ICD = International Classification of Diseases.

The most commonly recorded ICD-10 term within 'acute chest infections' concerned 'unspecified acute lower respiratory infection', which is a commonly used term overall; this dominated the other terms included in the group.

The duration of the antipsychotic prescriptions has not been considered in the graphical display of pneumonia-related medical-event registrations; hence, in cases of late onset, the patient may not have been a current user of the medicine when the event occurred.

Records of fatal outcome obviously cannot precede prescription. As such, cautious interpretation is needed when comparing the 'before' and 'after' prescription pattern of medical events 
most commonly associated with fatal outcome, as shown for bronchopneumonia.

A case-by-case evaluation to determine the possible causal relationship between the drug and the recorded event for individual patients has not been done in this study, and co-recorded events or prescriptions have not been evaluated. Instead, this analysis offers a way to highlight overall patterns of records before and after prescription, accounting for biases like expected clusters of events around prescriptions in general.

Without further analysis, it is not possible to identify any causative mechanism or factor leading to chest infections among older people who have been prescribed an antipsychotic drug. However, this study shows the temporal recording pattern of pneumonia and other acute chest infections in outpatients, not only after prescription but also before, sharpening the picture of the course of events in these patients.

\section{Comparison with existing literature}

The higher rate of chest infections after prescription of atypical antipsychotics is in line with Knol et al's study, ${ }^{7}$ where a stronger association between atypical antipsychotics and pneumonia was also seen, as compared with conventional antipsychotics. Users of conventional antipsychotics had a higher risk of death from infections, including pneumonia, than users of atypical antipsychotics in Setoguchi et al's study, ${ }^{4}$ but the difference was not statistically significant. A comparison with this study is complicated, given that different conventional antipsychotics are dominant in Setoguchi et al's study, and because they investigated mortality while the current study examined pneumonia-related terms, irrespective of outcome. Loxapine was the most commonly prescribed conventional antipsychotic in Setoguchi et al's study, ${ }^{4}$ whereas thioridazine was the most commonly prescribed conventional antipsychotic in the current dataset, with loxapine being a rarely prescribed drug.

Drug effects, possibly leading to pneumonia after antipsychotic prescriptions, in older people were reviewed by Knol et al. ${ }^{7}$ They mention xerostomia, dysphagia, dyskinesia, and sedation, which could result in swallowing problems, thereby causing aspiration pneumonia. In the current study there were few registrations specifically stating diagnoses suggestive of aspiration. However, it is plausible that GPs used a more general pneumonia term to record consequences of aspiration. Granulocytopenia is another disorder possibly caused by antipsychotics that could lead to a greater susceptibility of infection, resulting in the development of pneumonia. However, the increases in rates of serious acute chest infections soon after first use of an antipsychotic seen in this analysis are unlikely to be due to granulocytopenia, as (after first exposure) it takes some time to develop, and the infection occurs at an even later date.

The occurrence of acute chest infections after the prescription of antipsychotics in the present study could also be explained by other events and need not be a direct effect of the antipsychotic medicine. Pneumonia in older people may present with sudden psychiatric disturbances, such as confusion, agitation, or psychosis, while fever may not be prominent. ${ }^{14}$ In such patients, antipsychotics may be prescribed when the infection is not recognised, ${ }^{7}$ or to help manage the patient if it is. Likewise, in such patients, both the use of antipsychotics and serious illness and death would be more likely to occur. Confounding possibilities also exist for psychiatric disorders and pneumonia in older people in primary care situations, such as neoplasia with cerebral secondaries, self neglect, alcoholism, and more.

Bronchopneumonia was commonly recorded in connection to fatal outcome in this study, and death often occurred in the first weeks of antipsychotic use among the subset of older people studied more in detail. A Swedish study on autopsy reports revealed that far more patients with a terminal illness and dementia died from bronchopneumonia (38.4\%) than older people in general $(2.8 \%) .{ }^{15}$ This might explain why bronchopneumonia is recorded in temporal association with antipsychotic prescriptions given for patients with dementia, and could be seen as a natural course of their disease. However, it is interesting that the recording of bronchopneumonia commences so soon after first prescriptions of antipsychotic medicines, as seen in this study.

\section{Implications for future research}

As this study on outpatient records with chest infections following atypical antipsychotic prescriptions in older people confirms Knol et al's study on hospitalised patients, ${ }^{7}$ a causal relationship seems suggestive. Such an association would be of particular importance to patients with bronchopneumonia, as this diagnosis seems highly connected to fatal outcome. In the absence of a mechanism, further investigation of the role of antipsychotics in older people is needed.

\section{Funding body}

The authors are indebted to IMS Health for sharing the cost of a pilot project into knowledge discovery on the UK IMS Health Disease Analyzer dataset with the Uppsala Monitoring Centre.

\section{Competing interests}

Kristina Star has stocks in AstraZeneca. All other authors declare they have no competing interest relevant to this study. 


\section{Acknowledgement}

We thank Johan Hopstadius at the Uppsala Monitoring Centre for the computational support in performing this study.

\section{Discuss this article}

Contribute and read comments about this article on the Discussion Forum: http://www.rcgp.org.uk/bjgp-discuss

\section{REFERENCES}

1. US Food and Drug Administration. Public health advisory: deaths wit antipsychotics in elderly patients with behavioural disturbances. Silver Spring: US Food and Drug Administration, 2005.

http://www.fda.gov/Drugs/DrugSafety/PublicHealthAdvisories/ucm053 171.htm (accessed 15 Apr 2010).

2. US Food and Drug Administration. Information for healthcare professionals: conventional antipsychotics. Silver Spring: US Food and Drug Administration, 2008.

http://www.fda.gov/Drugs/DrugSafety/PostmarketDrugSafetyInformati onforPatientsandProviders/ucml24830.htm (accessed 15 Apr 2010).

3. Schneider LS, Dagerman KS, Insel P. Risk of death with atypical antipsychotic drug treatment for dementia: meta-analysis of randomized placebo-controlled trials. JAMA 2005; 294: 1934-1943.

4. Setoguchi S, Wang PS, Alan Brookhart M, et al. Potential causes of higher mortality in elderly users of conventional and atypical antipsychotic medications. J Am Geriatr Soc 2008; 56: 1644-1650.

5. Barnett MJ, Perry PJ, Alexander B, Kaboli PJ. Risk of mortality associated with antipsychotic and other neuropsychiatric drugs in pneumonia patients. J Clin Psychopharmacol 2006; 26: 182-187.
6. Wada H, Nakajoh K, Satoh-Nakagawa T, et al. Risk factors of aspiration pneumonia in Alzheimer's disease patients. Gerontology 2001; 47: 271-276.

7. Knol W, Van Marum RJ, Jansen PA, et al. Antipsychotic drug use and risk of pneumonia in elderly people. J Am Geriatr Soc 2008; 56: $661-666$.

8. Electronic Medicine Compendium. Summary of product characteristics Leatherhead: Datapharm Communications Ltd, 2009. http://www.medicines.org.uk/ (accessed 15 Apr 2010).

9. De Lusignan S, Stephens P, Adal N, Majeed A. Does feedback improve the quality of computerized medical records in primary care? J Am Med Inform Assoc 2002; 9: 395-401.

10. Norén GN, Hopstadius J, Bate A, et al. Temporal pattern discovery in longitudinal electronic patient records. Data Mining and Knowledge Discovery 2010; 20: 361-387.

11. European Pharmaceutical Market Research Association. Anatomical classification. http://www.ephmra.org/classification/anatomicalclassification.aspx (accessed 14 Apr 2010).

12. Sweetman S, ed. Martindale: the complete drug reference. London Pharmaceutical Press, 2010.

13. Leucht S, Corves C, Arbter D, et al. Second-generation versus firstgeneration antipsychotic drugs for schizophrenia: a meta-analysis. Lancet 2009; 373: 31-41

14. Venkatesan P, Gladman J, Macfarlane JT, et al. A hospital study of community acquired pneumonia in the elderly. Thorax 1990; 45: $254-258$

15. Brunnström HR, Englund EM. Cause of death in patients with dementia disorders. Eur J Neurol 2009; 16: 488-492. 


\begin{tabular}{|c|c|c|c|}
\hline $\begin{array}{l}\text { ICD-10 } \\
\text { code }\end{array}$ & ICD-10 term & $\begin{array}{l}\text { Read } \\
\text { Code }\end{array}$ & Read term \\
\hline \multirow[t]{7}{*}{$\mathrm{J110}$} & Influenza with pneumonia. Virus not identified & $. \mathrm{H} 3 .$. & Pneumonia and influenza \\
\hline & &. $\mathrm{H} 351$ & Influenza + pneumonia \\
\hline & &. $\mathrm{H} 3 \mathrm{Z}$. & Pneumonia/influenza NOS \\
\hline & & $\mathrm{H} 270$. & Influenza + pneumonia \\
\hline & & $\mathrm{H} 2700$ & Influenza + bronchopneumonia \\
\hline & & $\mathrm{H} 270 \mathrm{z}$ & Influenza + pneumonia NOS \\
\hline & & H2y.. & Pneumonia or influenza OS \\
\hline J120 & Adenoviral pneumonia & $\mathrm{H} 200$. & Pneumonia - adenovirus \\
\hline J121 & Respiratory syncytial virus pneumonia & H201. & Pneumonia - resp.syncyt.virus \\
\hline J128 & Other viral pneumonia & H2Oy. & Pneumonia - virus NEC \\
\hline \multirow[t]{3}{*}{ J129 } & Viral pneumonia, unspecified &. $\mathrm{H} 31$. & Viral pneumonia \\
\hline & & $\mathrm{H} 2 \mathrm{O} .$. & Viral pneumonia \\
\hline & & $\mathrm{H} 2 \mathrm{Oz}$. & Viral pneumonia NOS \\
\hline \multirow[t]{2}{*}{$\mathrm{J} 130$} & Pneumonia due to streptococcus pneumoniae &. $\mathrm{H} 32$. & Lobar-pneumococcal - pneumonia \\
\hline & & $\mathrm{H} 21 .$. & Lobar (pneumococcal) pneumonia \\
\hline $\mathrm{J} 140$ & Pneumonia due to haemophilus influenzae & H222. & Pneumonia - H.influenzae \\
\hline J150 & Pneumonia due to klebsiella pneumoniae & $\mathrm{H} 220$. & Pneumonia - klebsiella pneum. \\
\hline J151 & Pneumonia due to pseudomonas & H221. & Pneumonia - pseudomonas \\
\hline $\mathrm{J} 152$ & Pneumonia due to staphylococcus & $\mathrm{H} 224$. & Pneumonia - staphylococcal \\
\hline J154 & Pneumonia due to other streptococci & H223. & Pneumonia - streptococcal \\
\hline \multirow[t]{2}{*}{ J156 } & Pneumonia due to other aerobic & $\mathrm{H} 22 \mathrm{yX}$ & Pneumn/o aerobc grm-ve bact \\
\hline & Gram-negative bacteria & & \\
\hline \multirow[t]{4}{*}{ J157 } & Pneumonia due to mycoplasma pneumoniae &. $\mathrm{H} 342$ & Mycoplasma pneumonia \\
\hline & & $\mathrm{H} 231$. & $\begin{array}{l}\text { Pneumonia - mycoplasma } \\
\text { pneumon }\end{array}$ \\
\hline & & H232. & Pneumonia - PPLO \\
\hline & & H28.. & Atypical pneumonia \\
\hline \multirow[t]{2}{*}{ J158 } & Other bacterial pneumonia & H22.. & Other bacterial pneumonia \\
\hline & & $\mathrm{H} 22 \mathrm{y}$. & Pneumonia - other specif.bact. \\
\hline \multirow[t]{3}{*}{ J159 } & Bacterial pneumonia, unspecified &. $\mathrm{H} 341$ & Bacterial pneumonia NOS \\
\hline & & $\mathrm{H} 22 \mathrm{yz}$ & Pneumonia - bacteria NOS \\
\hline & & $\mathrm{H} 22 \mathrm{z}$. & Bacterial pneumonia NOS \\
\hline J160 & Chlamydial pneumonia & H233. & Chlamydial pneumonia \\
\hline \multirow[t]{2}{*}{ J168 } & Pneumonia due to other specified infectious organisms & $\mathrm{H} 23 .$. & Pneumonia - specif.organisms \\
\hline & & $\mathrm{H} 23 \mathrm{z}$. & Pneumonia-spec.organism NOS \\
\hline \multirow[t]{3}{*}{ J181 } & Lobar pneumonia, unspecified & $\mathrm{H} 260$. & Lobar pneumon-unspec organism \\
\hline & & H2600 & Lung consolidation \\
\hline & & H261. & Basal pneumon-unspec organism \\
\hline \multirow[t]{2}{*}{ J188 } & Other pneumonia, organism unspecified & HyuOH & {$[X]$ Oth pneumonia,organsm unspf } \\
\hline & & H2OyO & Severe acute respiratory syndr \\
\hline \multirow[t]{8}{*}{ J189 } & Pneumonia, unspecified &. $\mathrm{H} 34$. & Pneumonia NOS \\
\hline & &. $\mathrm{H} 34 \mathrm{Z}$ & Pneumonia NOS \\
\hline & & $\mathrm{H} 2 \ldots$ & Pneumonia and influenza \\
\hline & & H24.. & Pneumonia + Infect.disease EC \\
\hline & & H26.. & Pneumonia, organism unspecif. \\
\hline & & $\mathrm{H} 262$. & Postoperative pneumonia \\
\hline & & H2z.. & Pneumonia or influenza NOS \\
\hline & &. $\mathrm{H} 346$ & Bilateral pneumonia \\
\hline \multirow[t]{13}{*}{ J220 } & Unspecified acute lower respiratory tract infection & $. \mathrm{H} 1 .$. & Acute respiratory infections \\
\hline & &. $\mathrm{H} 163$ & Acute low respitract infection \\
\hline & &. $\mathrm{H} 1 \mathrm{Z}$. & Acute resp. infection NOS \\
\hline & &. $\mathrm{H} 6 \mathrm{ZA}$ & Chest infection NOS \\
\hline & &. $\mathrm{H} 6 \mathrm{ZB}$ & Lower respiratory tract infect \\
\hline & & $\mathrm{HO} \ldots$ & Acute respiratory infections \\
\hline & & H062. & Acute low respitract infection \\
\hline & & $\mathrm{H06zO}$ & Chest infection NOS \\
\hline & & $\mathrm{H} 06 \mathrm{z} 1$ & Lower resp tract infection \\
\hline & & H06z2 & Recurrent chest infection \\
\hline & & HOy.. & Acute respiratory infectns.OS \\
\hline & & $\mathrm{HOz}$. & Acute respiratory infectn.NOS \\
\hline & & SP132 & Post operative chest infection \\
\hline
\end{tabular}

${ }^{a}$ GP 4-byte set and 5-byte set Read Codes. ICD = International Classification of Diseases. 


Appendix 2. ICD terms and Read Codes ${ }^{\text {a }}$ for bronchopneumonia.
\begin{tabular}{llll} 
& & \\
ICD-10 & Read & \\
code & ICD-10 term & Code & Read term \\
\hline$J 180$ & Bronchopneumonia, unspecified & H33. & Bronchopneumonia \\
& H25.. & Bronchopneumonia,organism unsp \\
\hline
\end{tabular}

${ }^{a}$ GP 4-byte set and 5-byte set Read Codes. ICD = International Classification of Diseases.

\begin{tabular}{|c|c|c|c|}
\hline ICD-10 & & Read & \\
\hline code & ICD-10 term & Code & Read term \\
\hline J182 & Hypostatic pneumonia, unspecified & $\begin{array}{l}. \mathrm{H} 6 \mathrm{Z4} \\
\mathrm{H} 5400 \\
\mathrm{H} 5401\end{array}$ & $\begin{array}{l}\text { Hypostatic bronchopneumonia } \\
\text { Hypostatic pneumonia } \\
\text { Hypostatic bronchopneumonia }\end{array}$ \\
\hline J690 & Pneumonitis due to food and vomit & $\begin{array}{l}. \mathrm{H} 53 . \\
\mathrm{H} 470 . \\
\mathrm{H} 4703 \\
\text { SP131 }\end{array}$ & $\begin{array}{l}\text { Aspiration pneumonia } \\
\text { Pneumonitis-food/vomit inhal. } \\
\text { Pneumonitis-vomitus inhalation } \\
\text { Other asp.pneumonia after care }\end{array}$ \\
\hline J691 & Pneumonitis due to oils and essences & $\begin{array}{l}\mathrm{H} 471 . \\
\mathrm{H} 4710\end{array}$ & $\begin{array}{l}\text { Pneumonitis-oil/essence inhal. } \\
\text { Lipoid pneumonia (exogenous) }\end{array}$ \\
\hline J698 & Pneumonitis due to other solids and liquids & $\begin{array}{l}\mathrm{H} 47 . . \\
\mathrm{H} 47 \mathrm{y} . \\
\mathrm{H} 47 \mathrm{yz} \\
\mathrm{H} 47 \mathrm{z}\end{array}$ & $\begin{array}{l}\text { Pneumonitis - solids/liquids } \\
\text { Pneumonitis-other solid/liquid } \\
\text { Pneumonitis-solid/liquid NOS } \\
\text { Pneumonitis-solid/liquid NOS }\end{array}$ \\
\hline
\end{tabular}

${ }^{a} G P$ 4-byte set and 5-byte set Read Codes. ICD = International Classification of Diseases. 